\title{
Antimicrobial susceptibility pattern of clinical isolates from cases of ear infection using amoxicillin and cefepime
}

\author{
Shaheen Perveen ${ }^{2 *}$, Syed Baqir Naqvi ${ }^{1}$ and Anab Fatima ${ }^{3}$
}

\begin{abstract}
The aim of the present study was to determine the sensitivity pattern of clinical isolates of otitis media. During the last few decades, the occurrence of otitis media seems to have been rising probably because of prevalence of multidrug-resistant Pseudomonas aeruginosa and $\beta$-lactamase producing Staphylococcus aureus in the pathogenesis of otitis media. Pseudomonas aeruginosa and Staphylococcus aureus were the most common causative microorganisms of ear infection. Keeping in view the importance of these pathogens, the present study had been designed to determine the sensitivity pattern of clinical isolates of otitis media. These isolates were collected from different hospitals and pathological laboratories of Karachi and their sensitivity against cefepime and amoxicillin were determined by using disk diffusion method. The results have shown that Pseudomonas aeruginosa was the most common causative microorganism of ear infection. Cefepime, a fourth generation cephalosporin appeared to be an effective antibiotic against Pseudomonas aeruginosa and Staphylococcus aureus.
\end{abstract}

Keywords: Otitis media; Resistant; Pseudomonas aeruginosa; Staphylococcus aureus

\section{Introduction}

The term Otitis media (OM) generally used to describe any inflammatory process involving the middle ear. The main categories of OM are 1) Acute Otitis Media (AOM), 2) Secretory otitis media (SOM), also named chronic otitis media with effusion (COME) and 3) Chronic otitis media $(\mathrm{COM})$ with or without cholesteatoma (Harkness and Topham 1998). Acute Otitis Media is a condition with acute middle ear effusion (MEE) and acute signs and symptoms of infection for example fever, pain, restless sleep, irritability, tugging or rubbing of ears. AOM may also be accompanied with acute discharge from the ear. Recurrent AOM is defined as a condition with at least three AOM episodes in 6 months or 4 episodes within a year (Klein 1984; Alho 1997). Secretory otitis media SOM (or COME) means that MEE has lasted at least 2-3 months behind intact tympanic membrane. A permanent perforation of tympanic membrane with recurrent or constant purulent discharge indicates COM. This can be

\footnotetext{
* Correspondence: phrshaheen@yahoo.com

${ }^{2}$ Department of Pharmaceutics, Faculty of Pharmacy, Jinnah University for Women, Karachi, Pakistan

Full list of author information is available at the end of the article
}

associated with cholesteatoma, a condition where keratinizing stratified squamous epithelium accumulates in the middle ear cleft (Pellman 1999). Chronic suppurative otitis media (CSOM) involves a perforation (hole) in the tympanic membrane and active bacterial infection within the middle ear space for several weeks or more. Otitis media is very important because it is the earliest, or the first infection that occurs to children. Statistics showed $80-90 \%$ of children have at least one episode of otitis media by the age of 2 years (Boston 1989). From the pathogenic point of view, the nasopharyngeal carriership of pathogenic bacteria was a risk factor for AOM (Harabuchi et al. 1994, Faden et al. 1997), and as it has been shown that the same bacteria that have been identified in the middle ear also found in the nasopharynx. Loos et al. (1989), it was a rational to assume that bacteria enter the middle ear from the nasopharynx through the Eustachian tube. One of the most significant pathogenic factor in the development of otitis media was the dysfunction of the Eustachian tube. Bluestone (1974), showed that young children have shorter, straighter and more compliant Eustachian tube than adults. This permits a reflux from the nasopharynx to 


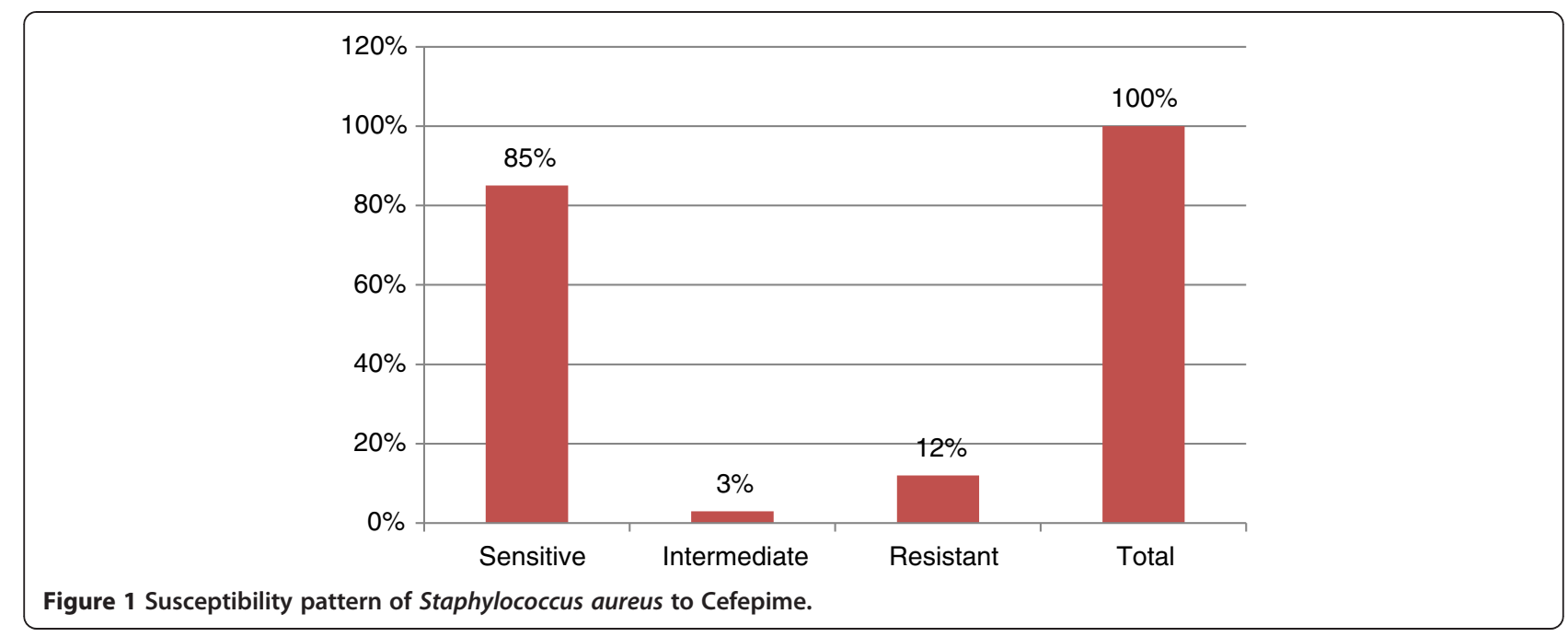

the middle ear with the consequence of bacterial contamination (Hooton 2000).

The improper and indiscriminate use of antimicrobials in our country regarded as a leading cause for higher percentage of resistant bacteria isolated from middle ear effusions of children.

The main objective of the present study was to study the susceptibility patterns of clinical isolates causing ear infection.

\section{Material and method}

In the present study, susceptibility patterns of clinical isolates from ear infection were determined. For this purpose, two hundred clinical isolates of ear infection were collected over a period of six months. Antibiotics discs were purchased from Oxoid.
The clinical isolates of Staphylococcus aureus and Pseudomonas aeruginosa from ear infection were collected from different hospitals and laboratories including $\mathrm{NICH}$, Ziauddin hospital, Dr. Essa's lab, Sind Lab and Mehdi Manji Lab. The culture swabs were collected at weekly intervals and safely transported to microbiology laboratory then the organisms were isolated in pure form and identified on the basis of characters given in Bergey's manual. Then pure isolates of Pseudomonas aeruginosa were transferred to $1 \%$ nutrient agar slant and were stored in the refrigerator at $4 \pm 1^{\circ} \mathrm{C}$. Different identification tests were performed on suspected Pseudomonas aeruginosa and were characterized and identified. Similarly verification tests for Gram-positive Staphylococcus aureus were also performed for pure isolation. The antibiotics used were Cefepime, a $4^{\text {th }}$ generation cephalosporin and Amoxicillin, a semi-synthetic penicillin.

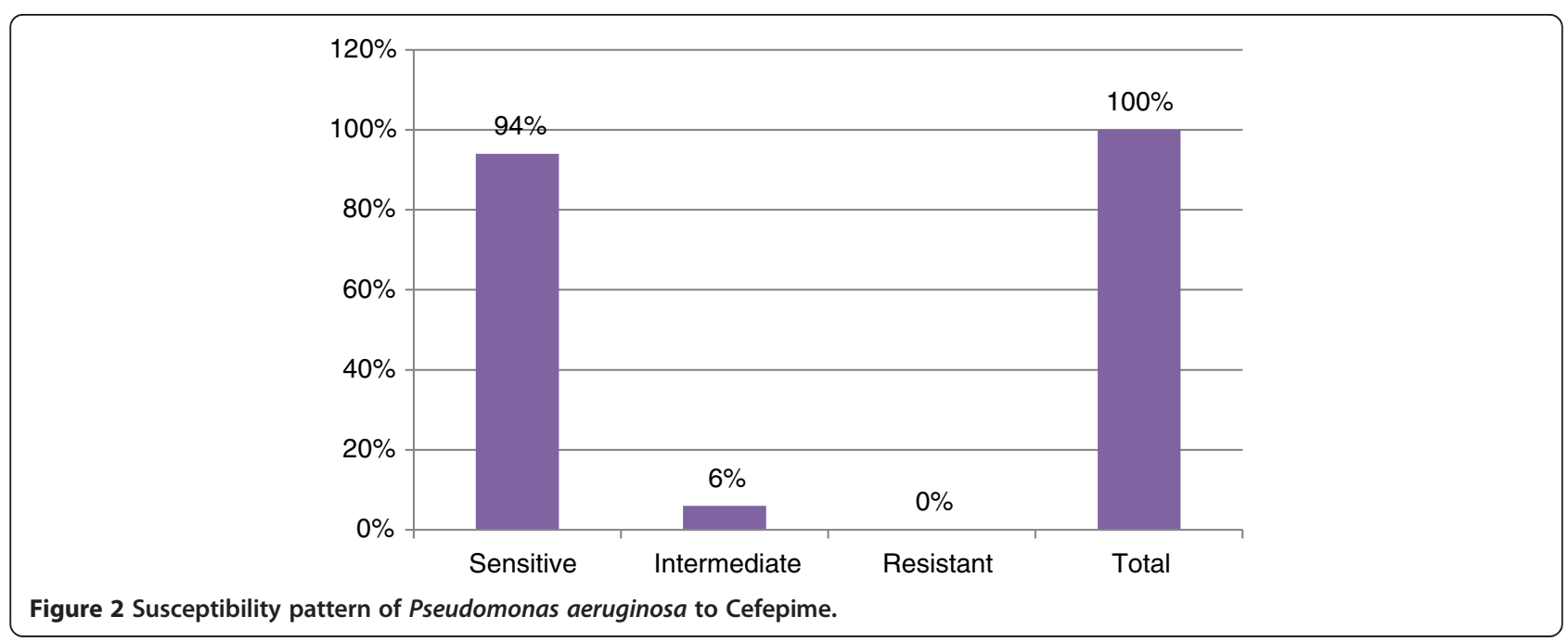




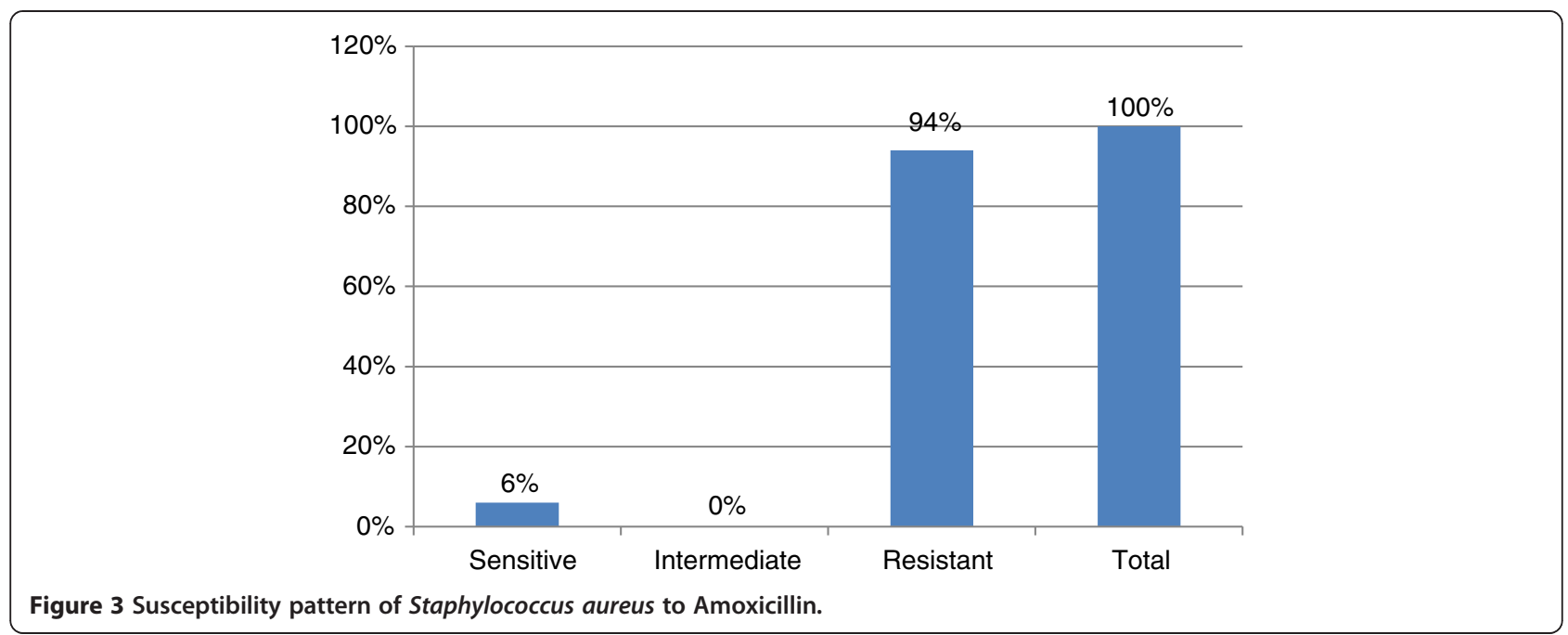

\section{Disk diffusion method}

Antimicrobial agent susceptibilities were determined by disk diffusion method. The method used was described in the NCCLS (2000) guidelines using Mueller-Hinton agar and broth (Oxoid, UK). The medium containing antimicrobial agent disk were quality controlled daily. The plates were examined after specified incubation and then the zone of inhibition were measured and then compared with NCCLS susceptibility of Staphylococcus aureus and Pseudomonas aeruginosa.

\section{Interpretation}

The diameters of the zone of inhibition around each disk were measured with a vernier caliper and were interpreted as sensitive or resistant according to the zone interpretive standards.

\section{Results}

The newer fourth generation cephalosporin, cefepime is effective against multidrug -resistant Pseudomonas aeruginosa and $\beta$-lactamase producing strains of Staphylococcus aureus.

Thus, cefepime is an alternative for the management of acute otitis media. Antibiotic susceptibilities of clinical isolates from ear infection were summarized in Figures 1, 2, 3 and 4. Cefepime showed $85 \%$ sensitivity against Staphylococcus aureus as shown in Figure 1. Cefepime is the most effective antibiotic against Pseudomonas aeruginosa having 94\% sensitivity as shown in Figure 2.

\section{Discussion}

Antibiotic resistance to available microorganisms has been constant since the introduction of sulfonamides in

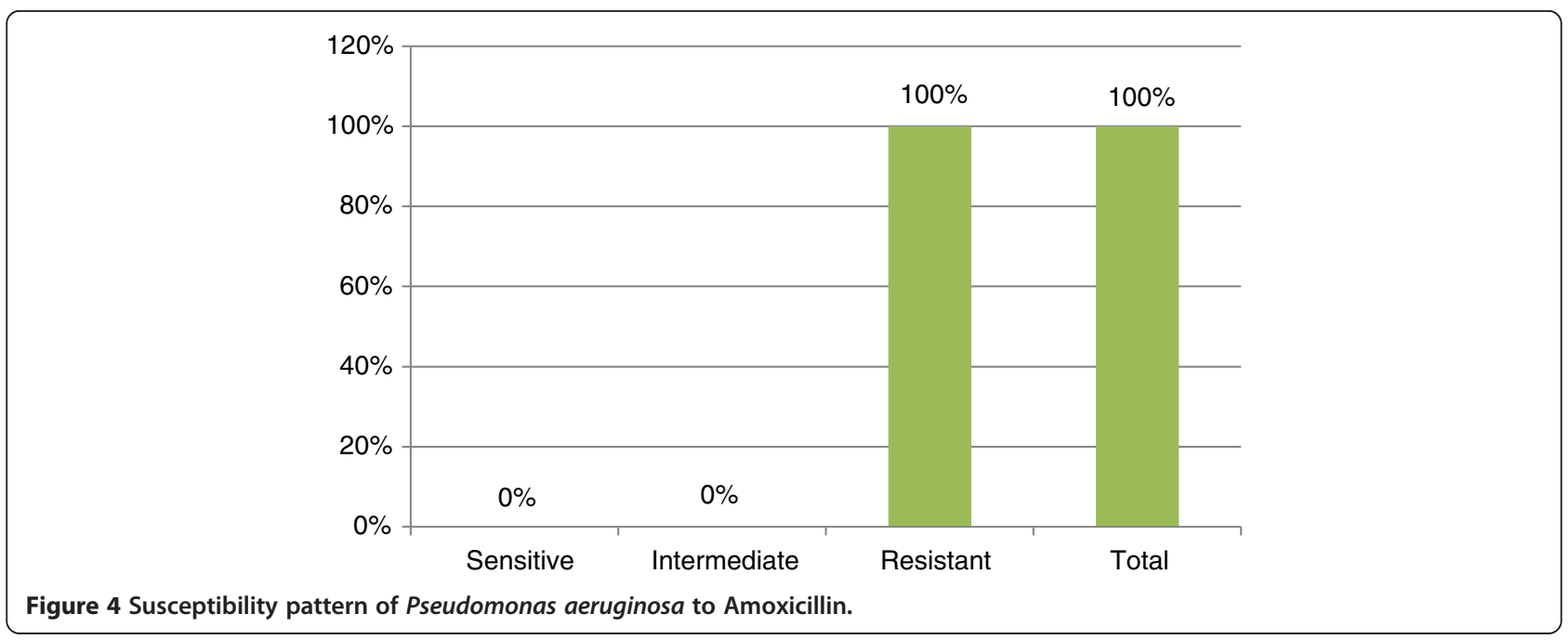


the 1930s. Multidrug resistant Pseudomonas aeruginosa and $\beta$-lactamase producing Staphylococcus aureus become a matter of great concern now because of the importance of these pathogens in middle ear infection of infants and children.

The risk factors for the development of resistance in otitis media include improper and indiscriminate use of antimicrobial, young age, tobacco smoke, male gender, day-care attendance and immunodeficiency. The understanding of the pathogenesis of acute otitis media (AOM) was the basis of discovering effective strategies in the management of this disease. According to Lim et al. in 2000 the middle ear cavity normally found sterile, and the sterility become maintained by the mucociliary system and by the enzymes and antibodies secreted by the epithelial cells of the Eustachian tube and the middle ear. Henderson et al. in 1982 and Heikkinen et al. in 1995 reported that although AOM is usually a bacterial infection but often proceeded by a respiratory viral infection. The same otitis pathogens that were found in middle ear effusion also found in the nasopharynx (Loos et al. 1989). Although AOM can occur at any age, it is most common in young children, particularly at the age of 6-24 months (Pukander et al 1982; Lundgren and Ingvarsson 1983; Teele et al. 1989). A genetic component engrossed in the predisposition to middle ear infections (Casselbrant and Mandel 2001).

Cefepime, the fourth generation cephalosporin has provided a new therapeutic possibility, offering a wide range of antibacterial activity and proven concentration in the middle ear.

Amoxicillin also used for treatment of otitis media but its major drawback was limited efficacy when $\beta$-lactamase producing bacteria were the major causative microorganisms. Klebsiella pneumoniae and Bacteroide spp. rarely caused acute otitis media (Robert 1992). Despite the availability of many other drugs, amoxicillin is still the drug of first choice in most cases (Klein 1994; McCracken 1994). In 1989, Brook and Yocum found that in suppurative otitis media, Pseudomonas aeruginosa, Klebsiella pneumoniae and Staphylococcus aureus were the most common bacteria. Mozafari Nia et al. in 2011 reported that the Staphylococcus aureus was the commonest aerobic isolate in CSOM. Pseudomonas isolates also showed complete (100\%) resistance to amoxicillin/clavulanate. Our findings also correlate with Mozafari findings.

In 2002, AHC Loy et al. found that the most common causative organism of chronic suppurative otitis media are Pseudomonas aeruginosa (33.3\%) and Staphylococcus aureus (33.3\%) followed by coagulase negative Staphylococcus aureus (21.1\%). Oni et al. (2001) reported that Pseudomonas aeruginosa was the predominant agent of chronic supprative otitis media and acute supprative otitis media. This was followed by Staphylococcus aureus. Kenna et al. (1986) reported that in chronic suppurative otitis media, the most common organisms are Pseudomonas aeruginosa and Staphylococcus aureus. According to Aslam et al. (2004) The commonest microorganisms isolated from chronic discharging ears were Pseudomonas aeruginosa and Staphylococcus aureus. This was also confirmed from our findings.

Among the cephalosporins, cefepime was used in the present study. All isolates of Pseudomonas aeruginosa were resistant to cefepime while only $12 \%$ isolates of Staphylococcus aureus were resistant to cefepime. Ale Zehra et al. (2010) also found cefepime effective against Pseudomonas aeruginosa. Pseudomonas aeruginosa and Staphylococcus aureus are the most frequently isolated pathogens in patients with acute otitis media. The recent emergence of multidrug-resistant Pseudomonas aeruginosa and increasing frequency of $\beta$-lactamase producing strains of Staphylococcus aureus are creating problem regarding the use of amoxicillin as first line empiric therapy for acute otitis media in young children. The new fourth generation cephalosporin, cefepime is effective against multidrug -resistant Pseudomonas aeruginosa and $\beta$-lactamase producing strains of Staphylococcus aureus.

\section{Conclusion}

Thus, Cefepime is an alternative for the management of otitis media. Hence the present study would be helpful for the Doctors and the Pharmacists in prescribing the medicine to the patients suffering from otitis media.

\section{Competing interest}

The authors declare that they have no competing interest.

\section{Authors' contributions}

SP carried out main research work. SBN Research Supervisor, guided us in every step of research work. AF She did collection and isolation of clinical isolates. All authors read and approved the final manuscript.

\section{Author details}

'Department of Pharmaceutics, Faculty of Pharmacy, University of Karachi, Karachi, Pakistan. ²Department of Pharmaceutics, Faculty of Pharmacy, Jinnah University for Women, Karachi, Pakistan. ${ }^{3}$ Department of Pharmaceutics,

Faculty of Pharmacy, Hamdard University, Karachi, Pakistan.

Received: 18 February 2013 Accepted: 19 June 2013

Published: 1 July 2013

\section{References}

Alho OP (1997) How common is recurrent acute otitis media. Acta Otolaryngol Suppl 529:8-10

Aslam MA, et al. (2004) Microbiology and drug sensitivity patterns of chronic suppurative otitis media. J Coll Physicians Surg Pak 14(8):459-461

Bluestone (1974) Mechanics of the Eustachian tube as it influences susceptibility to and persistence of middle ear effusions in children. Ann Otol Rhinol Laryngol 83(Suppl-34)

Boston (1989) Incidence of acute otitis media in children from age 1 to 7 years. J Infect Dis 163:83-94

Brook I, Yocum P (1989) Quantitative bacterial culture and $\beta$-lactamase activity in chronic suppurative otitis media. Ann Otol Rhinol Laryngol 98(4 Pt. 1):293-297

Casselbrant ML, Mandel EM (2001) The genetics of otitis media. Curr Allergy Asthma Rep 1:353-357 
Faden H, et al. (1997) Relationship between nasopharyngeal colonization and the development of otitis media in children. J Infect Dis 175:1440-1445

Harabuchi, et al. (1994) Nasopharyngeal colonization with nontypeable Haemophilus influenzae and recurrent otitis media. J Infect Dis 170:862-866

Harkness P, Topham J (1998) Classification of otitis media. Laryngoscope 108:1539-1543

Heikkinen T, et al. (1995) Incidence of acute otitis media associated with group A and $B$ respiratory syncytial virus infections. Acta Paediatr 84:419-423

Henderson FW, et al. (1982) A longitudinal study of respiratory viruses and bacteria in the etiology of acute otitis media with effusion. N Engl J Med 306:1377-1383

Hooton TM (2000) Pathogenesis of urinary tract infections: an update J Antimicrobial Chemotherapy 46(1):1-7

Kenna MA, et al. (1986) A medical management of chronic suppurative otitis media without cholesteatoma in children. Laryngoscope 96:146-151

Klein JO (1984) Antimicrobial prophylaxis for recurrent acute otitis media. Pediatr Ann 13:398-403

Klein JO (1994) Otitis media. Clin Infect Dis 19:823

Lim DJ, et al. (2000) Cell biology of tubotympanum in relation to pathogenesis of otitis media- a review. Vaccine 19(1):S17-S25

Loos BG, et al. (1989) Determination of the epidemiology and transmission of nontypeable Haemophilus influenzae in children with otitis media by comparision of total genomic DNA restriction fingerprints. Infect Immun $57: 2751-2757$

Loy AHC, et al. (2002) Microbiology of Chronic Suppurative Otitis Media in Singapore. Singapore Med J 43(6):296

Lundgren K, Ingvarsson L (1983) Epidemiology of acute otitis media in children. Scand J Infect Dis Suppl 39:19-25

McCracken GH (1994) Considerations in selecting an antibiotic for treatment of acute otitisd media. Pediatr Infect Dis J 13:1054

NCCLS (2000) Performance standards for antimicrobial disk susceptibility tests; Approved standard, 7th edition, vol 17, p 1

Nia M, et al. (2011) solation and Antimicrobial Susceptibility of Bacteria from Chronic Suppurative Otitis Media Patients in Kerman, Iran. Iranian Red Cres Med J 13(12):891-894

Oni AA, et al. (2001) Bacterial agents of discharging ears and antimicrobial sensitivity patterns in children in Ibadan, Nigeria. West Afr J Med 20(2):131-5

Pellman H (1999) All otitis media is not created equal. J Pediatrics:135-164

Pukander J, et al. (1982) Incidence of acute otitis media. Acta Otolaryngol 93:447-453

Robert B (1992) The Merck Manual of Diagnosis and Therapy, 16th edition, vol 209. Merck Research Laboratories, p 2331

Teele DW (1989) Epidemiology of otitis media during the first seven years of life in children in greater Boston: a prospective, cohort study. J Infect Dis 160:83-94

Zehra A (2010) Comparative study on resistance pattern of different pathogens against cefixime and cefepime. Jordan J Pharma Sci 3(2):145-156

doi:10.1186/2193-1801-2-288

Cite this article as: Perveen et al:: Antimicrobial susceptibility pattern of clinical isolates from cases of ear infection using amoxicillin and cefepime. SpringerPlus 2013 2:288.

\section{Submit your manuscript to a SpringerOpen ${ }^{\circ}$ journal and benefit from:}

- Convenient online submission

- Rigorous peer review

- Immediate publication on acceptance

- Open access: articles freely available online

- High visibility within the field

- Retaining the copyright to your article

Submit your next manuscript at $>$ springeropen.com 